\title{
Chapter 28 \\ Building Bridges Between the Math \\ Education and the Engineering Education \\ Communities: A Dialogue Through \\ Modelling and Simulation
}

\author{
Ruth Rodriguez Gallegos
}

\begin{abstract}
This chapter shows the importance of building communication bridges between two apparently disconnected academic communities: the mathematicians' and the engineers'. The starting point is an overview of an approach to teach mathematics through modeling and simulation of real problems at a private university in the northeast of Mexico that mainly focuses on the training of future engineers. The need to build communication bridges between the mathematics and the engineering education communities seems to be fundamental in order to rethink mathematics education's goals of being prepared to face the challenges posed by today's increasingly changing environment. The results and experience of mathematics professors teaching engineering students show some of the advantages of incorporating new ways of visualizing and understanding phenomena. Furthermore, these new ways allow students to have a new vision of mathematics and a deeper understanding of several math concepts.
\end{abstract}

Keywords Engineering - Mathematics - Modelling - Simulation Holistic

\subsection{Introduction}

The objective of this chapter is to show the importance of building communication bridges between two apparently disconnected academic communities: the mathematicians' and the engineers'. The main goal is to show the importance of introducing a new register of a concept in a mathematics course in order to improve the students' understanding and learning. This new register is the result of the interaction between mathematics education and engineering education. This idea sheds

\footnotetext{
R. Rodriguez Gallegos ( $₫)$

Tecnológico de Monterrey, Monterrey, México

e-mail: ruthrdz@itesm.mx

(C) The Author(s) 2018

G. Kaiser et al. (eds.), Invited Lectures from the 13th International Congress

on Mathematical Education, ICME-13 Monographs,

https://doi.org/10.1007/978-3-319-72170-5_28
} 
light on how to teach mathematics based on a specific engineering point of view and context.

\subsection{Literature Review}

From an international perspective, studies such as the report of the Program for International Student Assessment (PISA; OECD 2009) state the need to train people in developing the skills of mathematical literacy to solve problems in the future. PISA defines mathematical literacy as

the capacity to identify, to understand, and to engage in mathematics, and to make well-founded judgments about the role that mathematics plays, as needed for an individual's current and future private life, occupational life, social life with peers and relatives, and this individual's life as a constructive, concerned, and reflective citizen. (p. 17)

This idea of applying mathematics in the context of the students leads us to visit the theme of teaching and learning of mathematics, which has been treated for more than 40 years by the mathematics education community, mainly from the perspective of modeling (Blum et al. 2007) and simulation of real phenomena. A particular example of this is a study that focused on the training of future engineers (Rodríguez 2015) and even using technology (Rodríguez and Quiroz 2015) at a private university in the northeast of Mexico. Previous studies (such as Rodríguez 2015; Rodríguez and Quiroz 2015) allow us to highlight the richness of a work where students can improve their understanding of the mathematical notions learned in class when faced with the idea that they can describe several phenomena.

In Sect. 28.1.2, we show some theoretical background on the teaching and learning of mathematics through an overview of modeling.

\subsubsection{The Field of Engineering Education}

In the context of engineering education, studies (Bourn and Neal 2008) focusing on a very specific population of future engineers have asserted the prevailing need that an individual's basic education should develop generic skills to complement and reinforce disciplinary skills. The generic skills (Bourn and Neal 2008, p. 12) listed below aim to develop the global dimension in shaping the future engineer and stress the need and importance of these skills in several areas different from mathematics.

Generic skills

1. Holistic thinking, critical enquiry, and analysis and reflection

2. Active learning and practical application

3. Self-awareness and empathy 


\section{Strong communication and listening skills}

Its first place in the list shows the importance of developing students' holistic thinking, as they will also play a vital role as engineers and citizens of the $21 \mathrm{st}$ century. The authors suggest that the key to understand global skills is to recognize the complex nature of the world we live in and that the future is uncertain and there is not necessarily a series of easily identified solutions.

Hence, the need to develop holistic thinking as an important skill for students and future citizens of the 21 st century is made explicit.

Zeroing in on these assertions has led us to rethink the teaching of mathematics. Unlike traditional methods that have a prescribed order of contents and structure, developing competences for the 21 st century entails introducing complexity, changes, uncertainty, interconnectedness, multiple meanings, and interpretations in an unstructured universe. We believe that holistic thinking can contribute to enriching the modeling-based teaching of mathematics to meet the unknown needs of the 21st century. Bourn and Neal (2008) state that holistic thinking "requires understanding not only the complexities within the engineering systems but also the relationship between engineering systems and their context" (p. 8). Previously, Jowitt (2004; cited in Bourn and Neal 2008) stated that "a more holistic/systems view of the world is now required - one in which engineers need to be more fully aware of the economic, social and environmental dimensions of their activities and more skilled in meeting their objectives (p. 8)."

In essence, systems thinking is the ability to see a problem or situation holistically from multiple perspectives and understand the relationships, interconnections, and complexities between the different parts that make up the whole (Meadows 2008).

Based on the request to train students of basic education in this area, we decided to explore the importance of developing holistic thinking in future engineers. Since holistic thinking is also related to systems thinking (ST), our proposal is to think how ST skills can be included in math education. Bourn and Neal (2008) report the work done by Senge (2006) in this regard-learning about organizations from a business approach - and it became the trigger to show the advantages and benefits of incorporating systems thinking in a math class. Therefore, we want to emphasize that the idea of introducing ST in a math course is not new, but it has been studied little in recent research, at least in the math education community. In this section, we want to revisit some important works in this direction.

Several authors (Bourguet and Pérez 2003; Bourguet 2005; Fisher 2001, 2011a, b; Caron 2014) in the literature consider that introducing concepts of system dynamics (SD) is very natural in mathematics. SD models explore possible futures and ask "what if" questions. SD is a specific technique of ST where the use of simulators such as iThink or STELLA helps to show a representation of the model and operate with it. Bourguet and Pérez (2003) establish in their work that the SD models and differential equations are two effective representations to express the changes of things over time. SD uses symbolic and graphical representations as 
Table 28.1 A language of systems thinking in mathematics courses (based on Fisher 2001, 2011a)

\begin{tabular}{l|l|l|l}
\hline Concept & Mathematical form & Vensim form & $\begin{array}{l}\text { Vensim } \\
\text { button }\end{array}$ \\
\hline $\begin{array}{l}\text { Stock } \\
\text { This represents the main amount } \\
\text { that is to be accumulated. The } \\
\text { values increase or decrease over } \\
\text { time, and this shows the way } \\
\text { things are }\end{array}$ & $\begin{array}{l}\text { Current amount }=\boldsymbol{A}(\boldsymbol{t}) \\
\text { (This is an unknown } \\
\text { or dependent variable; } \\
\text { time or } t \text { is usually the } \\
\text { independent variable) }\end{array}$ & $\begin{array}{l}\text { Current } \\
\text { Amount }\end{array}$ \\
$\begin{array}{l}\text { Flow } \\
\text { This represents actions or } \\
\text { activities that cause the stock } \\
\text { value to increase or decline over } \\
\text { time }\end{array}$ & $\begin{array}{l}\text { Flow }=\frac{d A}{d t} \\
\text { (This is a rate of } \\
\text { change or derivative) }\end{array}$ & \\
\hline $\begin{array}{l}\text { Arrow/connector } \\
\text { This serves as an information or } \\
\text { action wire showing the relations } \\
\text { between the unknown (variable } A \\
(t)) \text { and its derivative(s) }\end{array}$ & $\begin{array}{l}\text { (These are the } \\
\text { assumptions or } \\
\text { hypotheses that we } \\
\text { make or the physical } \\
\text { laws that govern the } \\
\text { phenomenon.) }\end{array}$ & \\
\hline $\begin{array}{l}\text { Variable/converter } \\
\text { This is used to represent } \\
\text { additional and important logic to } \\
\text { the model. (It is often a modifier } \\
\text { for the flow.) }\end{array}$ & $\begin{array}{l}\text { (This is a parameter of } \\
\text { the equation, usually } \\
\text { called } \boldsymbol{k} \text { ) }\end{array}$ &
\end{tabular}

well as computer simulation models to represent and understand the dynamics of a situation (Table 28.1).

Some reflections made from a particular theoretical perspective are presented to undertake more comprehensive studies in engineering education for the 21 st century. It is our belief that math colleagues could require several generic skills to expand their vision of the first approach to modeling and simulation of complex phenomena as well as those of a social nature (Rodríguez 2015; Rodríguez and Bourguet 2014).

\subsubsection{Teaching and Learning in Math Education: A Differential Equations Course}

All over the world, and specifically in Mexican universities, the teaching of differential equations (DE) predominantly focuses on analytical methods rather than on qualitative and numerical methods. In spite of the wealth of knowledge of both approaches in the teaching of DE (Artigue 1995; Arslan et al. 2004), this and other 
developments have been evidenced in the community of mathematics education for over 20 years (Blanchard 1994; Blanchard et al. 2006).

In contrast, some changes have been reported in daily classroom activities. While successful innovative proposals for teaching DE (especially internationally) have been documented over the past few years (Blanchard 1994; Kallaher 1999; Blanchard et al. 2006; Nathan and Klingbeil 2014) and some other research on the subject has been published, few changes can be observed in classrooms and academic programs at various universities nationwide, particularly in the area of engineering.

This proposal aims to acknowledge the importance of the changes in three registers (algebraic, numeric, and graphic: "rule of three"; Douady 1986; Janvier 1987; Duval 1988, 1995; Artigue 1992; Fisher 1997, 2001, 2011a, b), the modeling approach (Blum et al. 2007; Rodríguez 2015), and the effective use of technology in the teaching/learning process of DE (Rodríguez and Quiroz 2015). We also incorporate a fourth register, the verbal (word problems: "rule of four"; Fisher 1997), and in the last years, we have recognized the importance of dealing with "reality" through physical experiments (such as building an electric circuit; Rodríguez 2015) and the effective use of technology in the teaching/learning process of DE (Rodríguez and Quiroz 2015) or a simulated "reality" through the use of simulators. In this study, we propose the necessity of integrating a new register (the fifth? "rule of five"? Senge 2006; Fisher 1997, 2001; Caron 2014) to work in a math course. We consider that the introduction of the fifth register in a DE course could help to promote another kind of perspective and way of regarding the problems and contexts studied in this course. In the next section, we want to further explain this specific technique from the system dynamics viewpoint. It is our hope to shed some light on the wealth of integrating the two seemingly separate disciplines, systems thinking and mathematics.

Figure 28.1 illustrates different ways in which technology allows "bringing reality" into the classroom in several ways:

a. Experimenting with physics and using sensors to "see" what happens to the magnitudes under study. Some of the sensors are portable technology. Texas Instruments calculators; voltage sensors; and temperature, motion, and various graphical interfaces are also used (Rodríguez and Quiroz 2015; Rodríguez 2015; Quezada-Espinoza and Zavala 2014; Wang et al. 2014).

b. Understanding the phenomenon through remote labs (e-labs), where a real phenomenon may occur. Students manipulate and study at a distance (Ramírez and Macías 2013).

c. Studying a phenomenon that is videotaped and studied through video analysis software such as Tracker (Olmos 2012).

d. Simulation of an experiment that failed when conducted in the classroom is possible as the University of Colorado (United States) proposed in PhET (Quezada-Espinoza et al. 2015; Rehn et al. 2013).

e. Building simulations with open/free simulators. At a slightly more advanced level, students are invited to build simulations using Vensim (Rodríguez and 


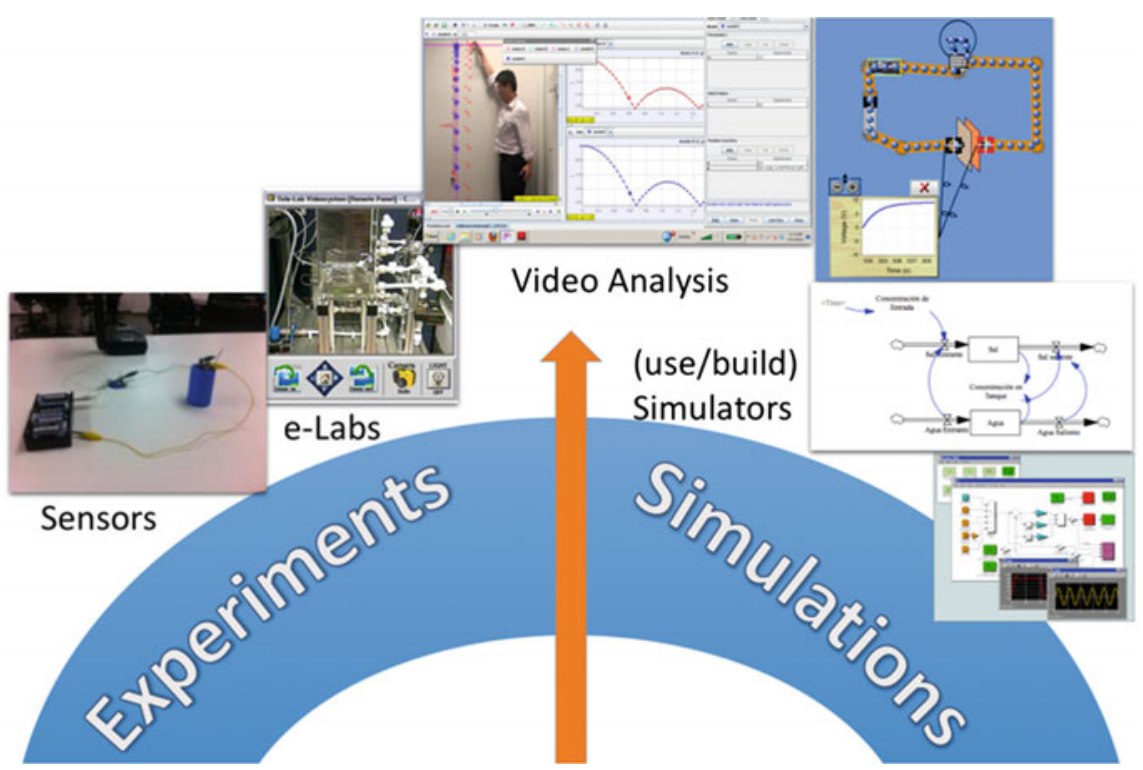

Fig. 28.1 Different uses of technology to portray "reality"

Bourguet 2014) and/or more sophisticated and specific software such as MatLab/Simulink (Smith and Campbell 2011) for the particular case of control theory.

\subsubsection{Some Theoretical Background About Representations in Math Education}

This section is devoted to the analysis of a theoretical framework regarding researchers in didactics of mathematics on the idea of representations.

Let us analyze a theoretical framework related to researchers in didactics of mathematics on the idea of representations. In 1987, Janvier presents the importance of the processes of conversion between representations. Duval $(1988,1995)$ independently emphasizes the importance of articulating representational registers and the importance of analyzing representations by identifying visual variables (for example, in a graphical representation of a function) that allow them to be linked to significant symbolic units. Duval (1995) provides an approach in the learning of mathematics by studying cognitive problems in depth when performing the processes of conversion between representations. Table 28.2 is a concrete example about the DE notion as explained by Rodríguez (2015).

In Douady's (1986) previous work, used by Artigue (1995) to discuss a problem in differential equations, she proposes the use of frames of representation, alluding to the importance of a student being able to transit, convert, and recognize a 
Table 28.2 Different representations of a DE notion in an electrical context

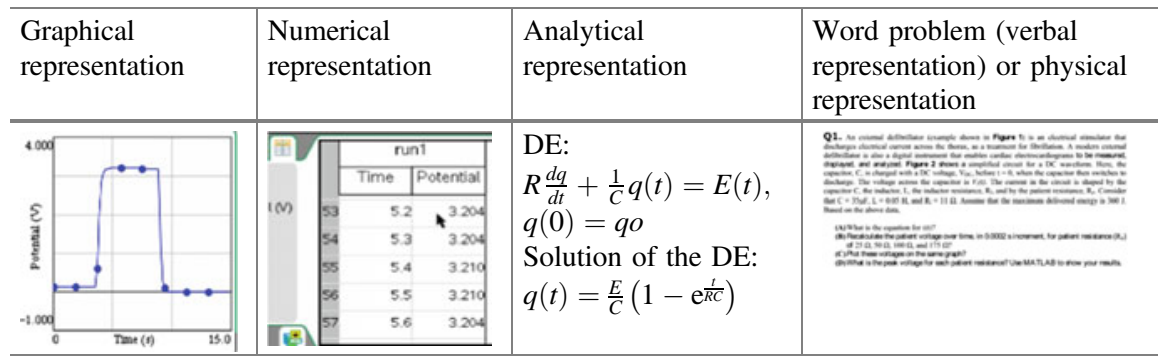

mathematical concept in its different classical representations as an object (numerical, graphical, and algebraic; "rule of three"; Fisher 1997; also verbal representation). In this work, Artigue basically explains how the graphic and qualitative records are left aside for a long time due to the increasing use of technology in the classroom, which puts the qualitative analysis at stake even though it is a fundamental part of the solution in a DE course. It is precisely at that point that we concluded that a fourth valuable representation is not only the verbal (word problem), but the real one in the sense that the student recognizes the real context that the DE models or simulates (Rodríguez 2015; the so-called "real" representation or simulated using an experiment). Finally, the purpose is to investigate whether a fifth representation - diagrams of stocks and flows using SD modelingwould help students make better sense of it considering that they are learning how to model real phenomena for the first time.

For this chapter, and in the following sections, we want to show a specific development of an educational research study about ways to improve the teaching of mathematics using modeling and simulations built by the students themselves (Item e in the list above). In particular, this is exemplified by the introduction of holistic and/or systemic thinking in the training of sophomore students of engineering in a specific course on differential equations. Through the introduction of a new language and vision of the phenomena, qualitative studies can give feedback that allows the introduction of a new vision, a new approach, and a new language for modeling (Fisher 2011a, b). The goal is then to study how the introduction of a new representation in a math course (DE course) in a university in Mexico helps the students better understand the topic.

\subsection{The Research Question}

Our major interest in our previous project was to explore and identify the most important uses of the mathematical objects engineers frequently utilize. This study is part of a bigger project whose purpose is to give some examples of the use of 
mathematics in other specialty subjects. In this case, for this chapter, we focus our attention on a specific kind of engineering. In Rodríguez and Bourguet (2014), we presented and justified our interest in a particular community of industrial engineering students with a minor in systems engineering, focusing in particular on the uses and meaning related to the DE math object. Considering the above, we identified some useful information on how math professors can obtain some important ideas of the DS approach (see Rodríguez and Bourguet 2014) to promote generic skills in addition to the mathematical ones to better educate the new global engineer of the 21 st century, in particular, those skills related to the importance of holistic thinking.

I decided that some important DS ideas would be designed and implemented in a DE course. Based on Fisher's work (1997, 2001, 2011a, b) and on interaction with an expert in system engineering who teaches a system dynamics course, the series of activities devised and used is shown in Sect. 28.4.1. Finally, the research question for this chapter is:

How does the introduction of DS-based activities using a new representation in a DE course affect our students, the future engineers?

The answer to this question will be the result of describing the methodology used when introducing a new fifth representation. This representation helped the students better understand the DE notion as an object or as a model of different situations and contexts.

\subsection{Methodological Approach}

The methodology for this exploratory and descriptive study was mainly a qualitative analysis (Creswell 2013) that had the purpose of leading us to have a more comprehensive outlook on the importance of how the student received this new representation.

It is very important to highlight that the design of the activities was the result of two years of collegiate work between a math professor and an industrial engineering professor. During this time, we had two-hour weekly meetings (32 weeks per year, 64 total) to discuss the elements in common between both disciplines. Each professor analyzed the course, the textbooks, the technology used, and their counterpart's evaluation. (Both professors attended each other's 16-week course). Finally, each professor established the advantages and disadvantages of each other's approach. This work was the basis to establish two phases. Specifically, the design phase (Phase 1), which inspired this study, was fully documented in Rodríguez and Bourguet (2014).

The methodological part of this study was divided into two phases, as follows:

Phase 1: The qualitative analysis from October 2013 to January 2014. We designed a series of two activities to be implemented in two sessions of 
$1.5 \mathrm{~h}$ each. We presented four exercises (see Sects. 28.4.2.1-28.4.2.4), with the last one (28.4.2.4) was specially built and analyzed by the students themselves. We focused on the part of using software to build a new representation of the exercise proposed, what the students' perception of this new language was, and how students would solve real problems in the DE course. This last exercise represented a kind of a real problem that is not usually studied in a traditional DE course, because the context is more on the social side, related to an ecological issue. The kind of DE proposed was not easy to solve by hand; thus, the use of specific technology was important and so was the mathematical difficulty of the DE, which was emphasized since one of the models was a non-linear DE.

Phase 2: The qualitative analysis from November to December 2014. We decided to use the results of an institutional survey related to three specific indicators to know more about the student's perceptions regarding this kind of modelling in a DE course (including the use of software to introduce and use a new representation of a DE).

In this chapter, we analyze the design of the activity eventually implemented and the results of the students' perceptions about the introduction of a new representation (issued from a system dynamics approach) in a math/DE course.

\subsubsection{Sample}

A total of 123 students completed an activity (during two sessions) and subsequently answered a survey at the end of the course. These students belonged to 24 different engineering majors. Of the four analyzed groups, two were honors courses. An honors course has a maximum number of 25 students. These students have a grade point average of between 90 and 100 points, and they speak at least one foreign language (usually English). Overall, the academic profile of these students is higher from the rest.

\subsubsection{The Design Process: Instruments for Phase 1}

\subsubsection{Test Over the 2014 Fall Term: Session 1, Part A. Total Time: 90 Min; Time for Part A: 45 Min}

During the first 45 min of the session, the Vensim software and the philosophies of systemic thinking and system dynamics were introduced. During this time, a mathematical model previously developed in class (Week 5) involving the filling of a water tank was discussed. How to model the system of a water tank being filled 


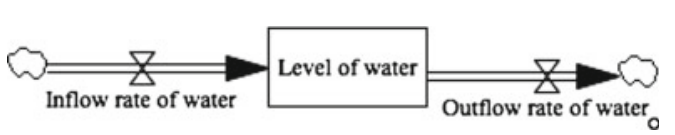

$\operatorname{LoW}(t)=$ Level of water

IroW $=$ Inflow rate of water

OroW $=$ Outflow rate of

water

$\frac{d V}{d t}=R_{i}-R_{o} ; V(t=0)=V_{0}$

Fig. 28.2 Example 1 of Vensim diagram

and emptied as a function of its incoming and outgoing flows of water was shown (see Fig. 28.2). This was interesting for the students because of the use of software and was a way to help the students become familiar with the graphic language used by Vensim.

\subsubsection{Session 1, Part B. Total Time: 90 Min; Time for Part B: 45 Min. Week 14 of 16}

In the second part of the session, during the last $45 \mathrm{~min}$, the students were asked to observe the software for a second time so that they could adapt it to the studied situation in class. They first studied the system of two tanks, but then salt was added to the incoming flow. At the time, what we were concerned about was the variable amount of salt in the tank $S(t)$. Figure 28.3 shows an example of a tank of water mixed with salt.

\subsubsection{Session 2, Part C. Total Time: 90 Min; Time for Part C: 45 Min}

The philosophy of system dynamics was presented again in a new problem during the first $45 \mathrm{~min}$ of the session. Over that time, a mathematical model previously developed in class (Week 3) involving the infection of a virus was discussed (see Fig. 28.4).
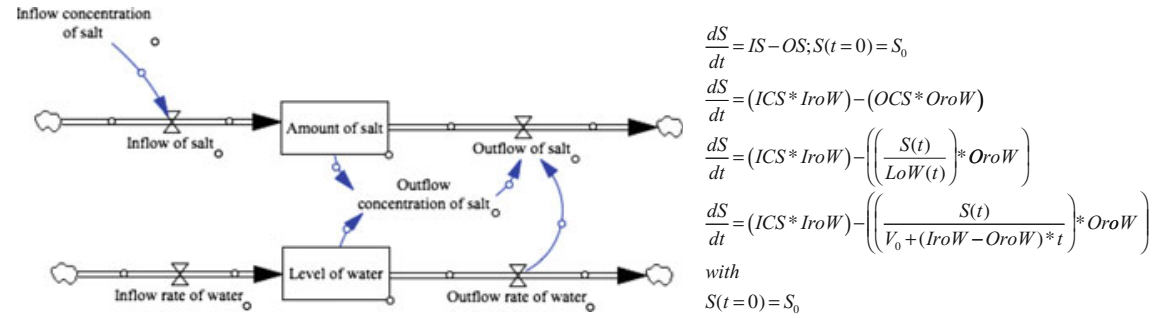

Fig. 28.3 Example 3 of a diagram in Vensim for a tank with water mixed with salt 

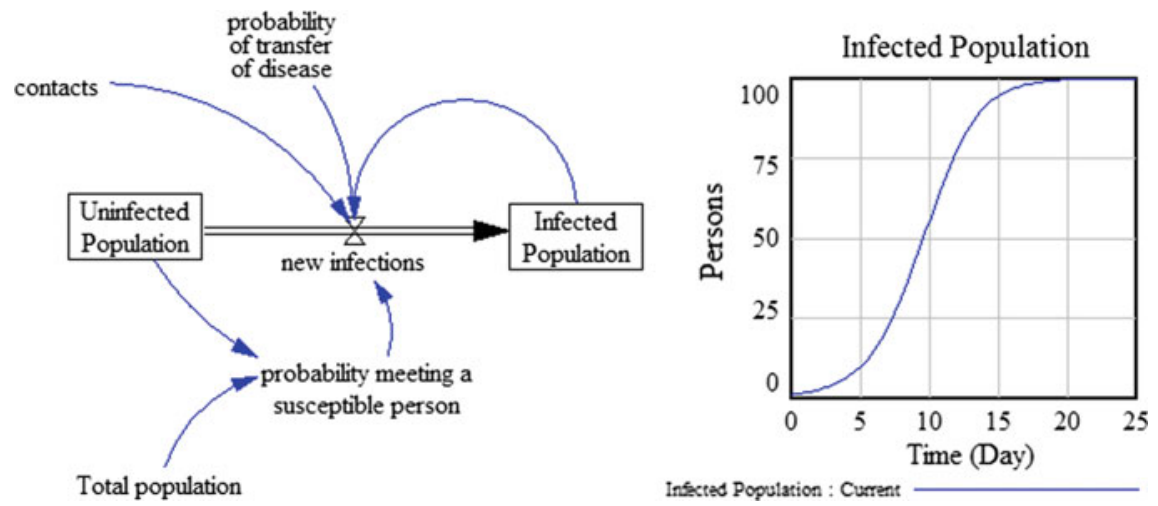

Fig. 28.4 Example of a diagram in Vensim (stock and flow diagram) and graphical representation

15. Suppose a species of fish in a particular lake has a population that is modeled by the logistic population model, with a growth rate $k$, carrying capacity $N$, and time $t$ measured in years. Adjust the model to account for each of the following situations.

a) 100 fish are harvested each year.

b) One third of the fish population is harvested annually.

c) The number of fish harvested each year is proportional to the square root of the number of fish in the lake.

(From Exercise 16). Suppose that the growth rate parameter is $k=0.3$ and the carrying capacity is $N$ $=2,500$ in the logistic population model of Exercise 15. Suppose $P(0)=2,500$.

d) Which situation, a, b, or c, is the most threatening to the environment? Support your answer.

Fig. 28.5 Exercise 15 and 16 in Blanchard et al. (2006, p. 18)

\subsubsection{Session 2, Part D. Total Time: 90 Min; Time for Part D: 45 Min}

Later on, the students were asked to solve another problem that was designed based on Blanchard et al. (2006, p. 18, exercise 15 and 16, see Fig. 28.5) but rewritten in the case format.

Question d was included in the problem, and it was the professors' decision to address it since it was not originally posed in the problem. During the 2014 Fall Term, the statement of this exercise was modified to introduce it as a case study. The way it was written changed it considerably, giving the student the freedom to make decisions according to the situation described. This time, the problem led the students to think of a scenario in which they had to make a decision based on three possible ways of fishing. They also had to support their answers based on the simulator according to the statement of the problem in the book (see Fig. 28.6).

It is important to emphasize that the $3 \mathrm{ODE}$ are not linear, hence the difficulty in obtaining the analytical solution for the analytical methods. Thus, the use of the simulator Vensim was well suited to solve this case and to allow each team of students take a position on the last question asked: 

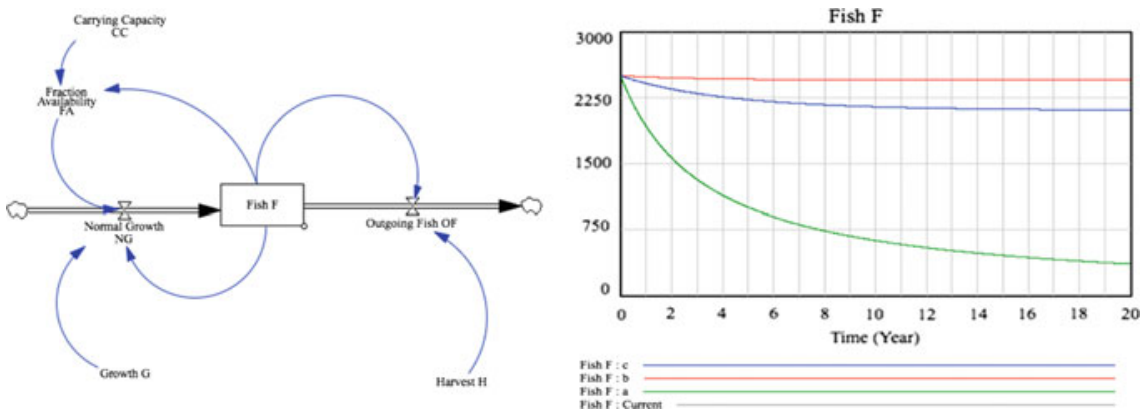

Fig. 28.6 Example of the student representation for the case proposed

Which situation, $\mathrm{a}, \mathrm{b}$, or $\mathrm{c}$, is the most threatening to the environment? Support your answer

In the next section, we show a student's analytical response obtained using the simulation software Vensim.

\subsubsection{Findings: A Student's Abridged Analytical Response in Phase 1}

It is important to note that this answer was finally obtained with the simulator by the students themselves during their experience. We may notice that Option a causes greater damage to the environment while the other two remain constant. Furthermore, Option b is less harmful than c.

In the rest of this section, we want to reflect about the comments and decisions made by the students in studying this case in a differential equations course. In both groups, the students concluded that Option b was less harmful.

However, the focus in this paper is on the richness of the discussion among the students in each team after analyzing the question and making their decision using the results shown by the simulator.

For example, over the class discussion, we aimed at having the fishing company behave in a responsible manner. From the financial point of view, the company would make greater profit by catching more fish. However, if they wanted the company to behave in an environmentally friendly manner, Option b was the right one. Finally, many students agreed on an "intermediate" option, Option c. Another important matter discussed was whether to seek more benefit or more stability in the short to medium term (8 years) or in the long term. (It is worthwhile noticing how the time domain was simulated over a period of 100 years). Something interesting to note was that in one group, a couple of teams proposed alternative solutions of the first 3 proposals. A student proposed that instead of catching 100 fish per year to consider 150 (a variant of b). Prior to this proposal, they had to modify the value of the parameters using Vensim, an issue that we wanted to promote in using this software in this case. 


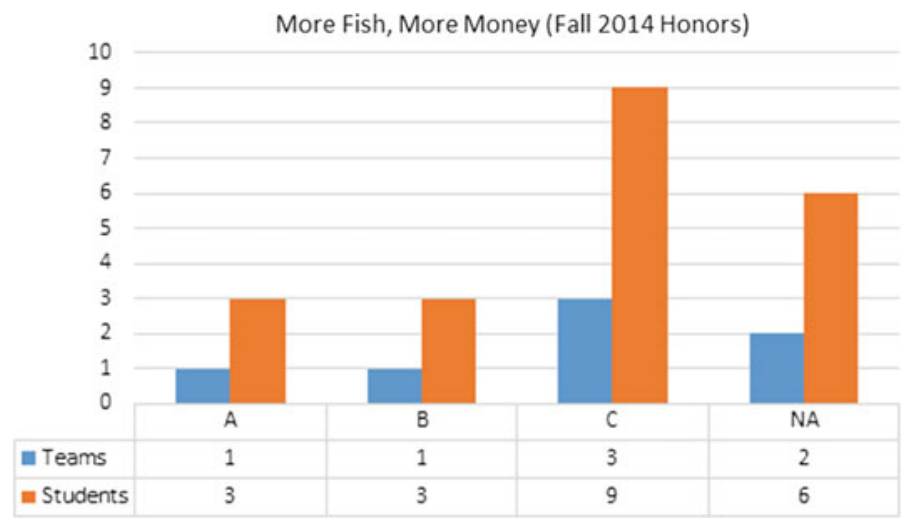

Fig. 28.7 Students' answers to the exercise

In the second part of Session 2, the logistic model was presented from the view of system dynamics. The answers of 21 students were analyzed and are presented in Fig. 28.7.

The problem presented was not an easy task to solve in class. This caused the different teams to rethink their answers, and, although the problem seemed easy, it was not possible to give a unique answer. Furthermore, the students had difficulties in establishing a conclusion without the help of the software. We had assumed that incorporating a systemic viewpoint in order to understand the complete setting of the problem would be helpful. Some matters of social, ethical, and sustainable development interest appeared within the arguments the students gave to the problem. This kind of modeling practice observed in most of the cases of engineering fields is seldom addressed in a traditional math class.

To conclude this part, we would like to comment that the qualitative results obtained in the answers for the activity/case led us to think that it is advisable to include software such as Vensim in the DE course. This allows a new representation of the DE object to be given from the system dynamics viewpoint.

Regarding our research question, we have established that the most relevant aspects of introducing the systems perspective in a math course (or DE course) and using this software are related to the students' learning of how to make adjustments in the parameters of the DE, understanding behaviors and setting relationships between variables in the equation, and understanding the meaning of the numerical and graphical solutions of a DE: All of these are beyond the analytical methods and solutions. We consider that this evidence observed in the answers of the students in this exercise gave us some useful information to show the richness of introducing a systemic approach in the teaching of a mathematics course such as the DE course. 


\subsubsection{Phase 2: Qualitative Analysis (2 Semesters: Fall 2014)}

In this last phase, we analyze some results of an institutional survey from a descriptive, statistical point of view.

\subsubsection{About the Student Opinion Survey}

We focused our attention on four questions. Since the Likert scale is used institutionally, it was decided that this survey would use the same scale. We considered that these questions could help us have a general idea of how the new exercises in a math class using simulation with systems thinking viewpoint would allow the student to have better understanding of how mathematics is relevant in real and work life.

Question TR: Theory and Reality (TR). "The professor implemented learning activities that allowed students to understand the relationship of the content of the course with reality." It is important to emphasize that the indicator theory and reality is usually lower for math classes, especially because of the traditional and near-sighted perspective that stops students from realizing the importance of math and its applications in their everyday life. It is also worthwhile noticing that this question is related to Generic Skill 2, active learning and practical application.

Question CC: Comprehension of Concepts (CC). "The professor facilitated the understanding of the content through clear explanations." It is mentioned in the mathematical section of this paper that the introduction of the systems perspective and the use of a simulator such as Vensim is to allow the students to have another representation (the fifth representation: stock-and-flow diagrams) of the DE for them to have better understanding of this math concept.

Question RDL: Research Documents in Library (RDL). "The professor promoted the use of the query library materials (books, magazines, digital library, and databases) to support learning activities." This question is about how to deal with complex problems, beyond those traditionally seen in a math class; therefore, there is the need to search information in other sources in addition to the one found in the textbook of the math class.

Question IC: Intellectual Challenge (IC). "The professor always demanded your best while maintaining a high intellectual challenge to favor your learning." This question refers to how to deal with complex problems beyond those traditionally seen in a math class. We also included space for the students to express a general opinion about the professor's overall performance during the semester. We called this indicator GOP, General Opinion about the Professor (GOP). We considered it a signal of the complete design of the differential equations course. It is very important to remember that this course is based on active learning and modeling and simulation practices. 
We compared two different honors groups and in Fall 2013, this group (F13H, see Fig. 28.8) did not consider an SD modelling approach including the new representation.

Figure 28.8 shows charts of the 2013 and 2014 fall semesters.

Figure 28.8 shows that there are three important differences concerning the introduction of systems thinking in the four analyzed indicators in these two years:

(a) The CC indicator decreases from 1.44 to 1.18 ( -0.26 points).

(b) The TR indicator decreases from 1.25 to 1.06 ( -0.19 points).

(c) The IC indicator decreases from 1.24 to 1.06 ( -0.18 points).

(d) The RDL indicator decreases from 1.18 to 1.06 ( -0.12 points).

\subsubsection{Findings: A Brief Analysis of Students' Responses in Phase 2}

As a result of the changes implemented in the course, we can conclude that students perceived that the professor facilitated the understanding of the content through clear explanations (CC indicator). We could infer that the design and incorporation of these activities in the DE course helped to better understand what a DE is by studying the different representations of this object (analytical, numerical, graphical, stocks and flows diagrams, and real situation). The students acknowledged the importance of the DE object since it was helpful to model other real situations (like social/ecological issues, shown in the TR indicator) in addition to those related to physical phenomena (traditionally studied in a math course). The students also highlighted the use of the intellectual challenge (IC indicator) that the course imposed for the activities carried out (including this one) as well as the necessity to search for additional materials different from the textbooks (RDL indicator).

With respect to our research question, we consider that the results of this institutional survey allowed us to give elements that visualize the effects of introducing SD activities such as those shown in Sect. 28.3.2. We consider it important to comment that in the institution where the activity was developed, the TR and CC indicators are difficult to improve since mathematics traditionally has little relation to real problems. We believe that an approach like the one shown above could help
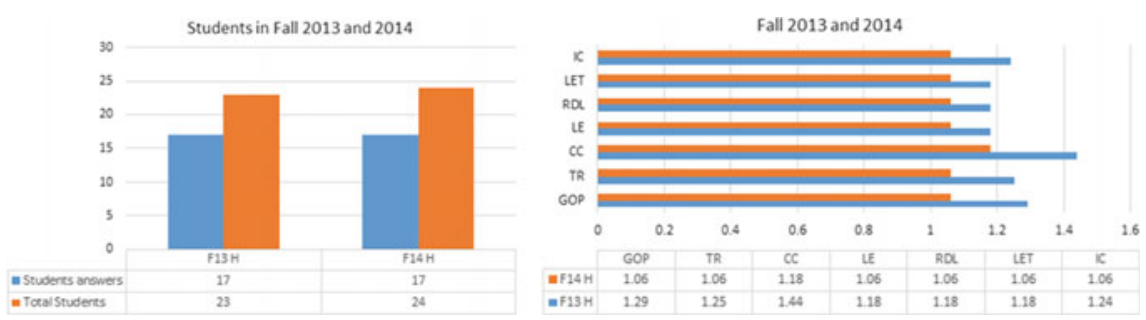

Fig. 28.8 Student sample and results in fall 2013 and 2014 (Honors) 
the students make sense of the math concepts by linking them with real contexts, especially one that interests them such as concern for the environment.

\subsection{Conclusions}

The intention of the chapter arises from the idea of improving the teaching and learning of mathematics at all educational levels by incorporating basic ideas from an engineering field. The first part showed our interest in improving the understanding the future engineers have of a math concept. As an example, we identified that the differential equation tool is of great value for professionals at all levels in many disciplines. We identified the uses of differential equations that industrial engineers with a minor in systems engineering use in a specific course: systems dynamics. We also mentioned that the math professors could obtain some important ideas of the SD approach to promote generic skills such as holistic thinking/systems thinking, active learning, and practical application. We think that these ideas can be obtained from engineering tools from other discipline areas. Based on the results obtained in the methodological part with the students' surveys, we observed that they perceived that the introduction of a new representation such as that offered by SD modeling in terms of a dynamic programming with stocks-flows allowed the students to better understand the notion of DE. This new representation helped students to give another meaning to the components involved in a specific context and their connections, but above all, we found that the richness of having this new way of representing a DE could give students a control tool to use to model more complex problems in addition to the numerical methods already available. Hence, we consider that future studies in this direction would be valuable.

\section{References}

Arslan, S., Chaachoua, H., \& Laborde, C. (2004). Reflections on the teaching of differential equations. What effects of the teaching of algebraic dominance? Memorias del X Congreso Internacional de Matemática Educativa (ICME XI). Dinamarca.

Artigue, M. (1992). Functions from an algebraic and graphic point of view: Cognitive difficulties and teaching practices. In E. Dubinsky \& G. Harel (Eds.), The concept of function: Aspects of epistemology and pedagogy, MAA notes 25 (pp. 109-132). Washington, DC: MAA.

Artigue, M. (1995). La enseñanza de los principios del cálculo: problemas epistemológicos, cognitivos y didácticos. In Gómez, P. (Ed.), Ingeniería didáctica en educación matemática. Grupo Editorial Iberoamérica. México.

Blanchard, P. (1994). Teaching differential equations with a dynamical systems viewpoint. The College Mathematics Journal, 25, 385-393.

Blanchard, P., Devaney, R., \& Hall, G. (2006). Differential equations (3a edición). Belmont: Cengage. 
Blum, W., Galbraith, P. L., Henn, H.-W., \& Niss, M. (2007). Introduction. In W. Blum, P. L. Galbraith, H.-W. Henn, \& M. Niss (Eds.), Modelling and applications in mathematics education (pp. 45-56). The 14th ICMI-study 14. Berlin: Springer.

Bourguet, R. E. (2005). Desarrollo de Pensamiento Sistémico usando ecuaciones diferenciales y dinámica de sistemas. En Reunión de Intercambio de Experiencias en Estudios sobre Educación del Tecnológico de Monterrey (RIE). Monterrey. Recuperado en: http://www.mty. itesm.mx/rectoria/dda/rieee/.

Bourguet, R. E., \& Pérez, G. (2003). On mathematical structures of systems archetypes. In Proceedings of the 21st International System Dynamics Conference. New York, USA: System Dynamics Society.

Bourn, D., \& Neal, I. (2008). The global engineer. Incorporating global skills within UK higher education of engineers. Engineers against Poverty. Leading Education and Social Research. Institute of Education. University of London.

Caron F., Lidstone D. \& Lovric M. (2014). Complex dynamical systems. In S. Oesterle \& D. Allan (Eds.), Actes du Groupe canadien d'étude en didactique des mathématiques (pp. 137-148). Alberta, 30 mai-3 juin 2014.

Creswell, J. W., \& Creswell, J. W. (2013). Qualitative inquiry and research design: Choosing among five approaches. Los Angeles: SAGE Publications.

Douady R. (1986). Jeux de cadre et dialectique outil-objet. Recherches en didactique des mathématiques, 7.2, 5-31.

Duval, R. (1988). Graphiques et équations: l'Articulation de deux registres. Annales de Didactique et de Sciences Cognitives, 1, 235-253.

Duval, R. (1995). Sémiosis et pensée humaine: Registres sémiotiques et apprentissage intellectuels. Neuchâtel: Peter Lang.

Fisher, D. (1997). Seamless integration of system dynamics into high school mathematics: Algebra, calculus, modeling courses. Recuperado en: ftp://www.clexchange.org/documents/ implementation/IM1997-07IntegrationSDMath.pdf.

Fisher, D. (2001). Lessons in mathematics: A dynamic approach. Australia: Stella Software.

Fisher, D. (2011a). Modeling dynamics systems: Lessons for a first course (3rd ed.). Australia: Stella Software.

Fisher, D. M. (2011b). "Everybody thinking differently": K-12 is a leverage point. System Dynamics Review, 27, 394-411. https://doi.org/10.1002/sdr.473.

Janvier, C. (Ed.). (1987). Problems of representation in the teaching and learning of mathematics. London: Lawrence Erlbaum Associates.

Jhori, A. (2009). Preparing engineers for a global world: Identifying and teaching strategies for sensemaking and creating new practices. In Proceedings of the 39th ASEE/IEEE Frontiers in Education Conference.

Jowitt, P. (2004). Systems and sustainability: Sustainable development, civil engineering and the formation of the civil engineer.

Kallaher, M. (1999). Revolutions in differential equations, exploring ODES with modern technology. MAA Notes 50, Washington, DC: MAA.

Meadows, D. (2008). Thinking in systems. A primer. USA: Chelsea Green Publishing.

Nathan, K., \& Klingbeil, N. (2014). Introductory math to engineering applications. New Jersey: Wiley.

Niss, M., Blum, W., \& Galbraith, P. (2007). Introduction. ICMI Study 14: Applications and modelling in mathematics education (pp. 3-32). New York: Springer.

Olmos, O. (2012). Laboratorio para la creación de recursos didácticos para física y matemáticas a través del video análisis: Video-Learning Lab. Memorias del 7o. Congreso en Innovación y Tecnología Educativa (CITE). Monterrey, N.L. 
Organization for Economic Cooperation and Development [OCDE]. (2009). PISA 2009 results. What students know and can do: Students perfomance in reading, mathematics and science. Retrieved for http://www.oecd.org/pisa/keyfindings/pisa2009keyfindings.htm.

Quezada-Espinoza, M., del Campo, V., \& Zavala, G. (2015). Technology and research-based strategies: Learning and alternative conceptions. In 2015 Physics Education Research Conference Proceedings (pp. 271-274). American Association of Physics Teachers. http://doi. org/10.1119/perc.2015.pr.063.

Quezada-Espinoza, M., \& Zavala, G. (2014). El uso de calculadoras con sensores en el aprendizaje de circuitos eléctricos. Latin American Journal of Physics Education, 8(4), 1-10.

Ramírez, D., \& Macías, M. (2013). Solving material balance problems at unsteady state using a remote laboratory in the classroom. American Society of Engineering Education (ASEE) International Forum Proceedings. Atlanta, Estados Unidos. Recuperado en: http://www.asee. org/public/conferences/20/papers/8178/viewsthash.rUAqjad8.dpuf.

Rehn, D. A., Moore, E. B., Podolefsky, N. S., \& Finkelstein, N. D. (2013). Tools for high-tech tool use: A framework and heuristics for using interactive simulations. Journal of Teaching and Learning with Technology, 2(1), 31-55.

Rodríguez, R. (2015). A differential equations course for engineers through modelling and technology. In G. Stillman, W. Blum, \& M. S. Biembengut (Eds.), Mathematical modelling in education, research and practice. Cultural, social and cognitive influences (pp. 545-555). New York: Springer. Print ISBN: 978-3-319-18271-1, Electronic ISBN: 978-3-319-18272-8. http://www.springer.com/us/book/9783319182711.

Rodríguez, R., \& Bourguet, R. (2014). Diseño interdisciplinario de Modelación Dinámica usando Ecuaciones Diferenciales y Simulación. Latin American and Caribbean Consortium of Engineering Education (LACCEI 2014). Guayaquil, Ecuador. http://www.laccei.org/ LACCEI2014-Guayaquil/index.htm.

Rodríguez, R., \& Bourguet, R. (2015). Building bridges between mathematics and engineering: Modeling practices identified through differential equations and simulation. American Society of Engineering Education (ASEE) Annual Conference and Exposition, Conference Proceedings. Atlanta, Estados Unidos. https://www.asee.org/public/conferences/56/papers/ 13153/view.

Rodríguez, R., \& Quiroz, S. (2015). El papel de la tecnología en el proceso de educación matemática para la enseñanza de las Ecuaciones Diferenciales. Revista Latinoamericana de Investigación en Matemática Educativa, 19(1). https://doi.org/10.12802/relime.13.1914; ISSN: 2007-6819.

Romo-Vázquez, A. (2014). La modelización matemática en la formación de ingenieros. Educación Matemática, 314-338. Recuperado de http://www.redalyc.org/pdf/405/40540854016.pdf.

Senge, P. $(2006,1990)$. The 5th discipline: The art and practice of the learning organization. New York: Doubleday/Currency.

Smith, C., \& Campbell, S. (2011). A first course in differential equations, modeling, and simulation. Boca Ratón: CRC Press.

Société Européenne pour la Formation des Ingénieurs. (2016, 23 de julio de). Obtenido de http:// www.sefi.be/.

Sterman, J. D. (2000). Learning in and about complex systems. In Business dynamics: System thinking and modeling for a complex world (Cap. 1, 5-10). Estados Unidos de América: Irwin/ McGraw-Hill.

Tecnologico de Monterrey. (2015). Challenge based learning. Recuperated in: http://observatory. itesm.mx/edu-trends. 
Universidad de Alcalá. Fundación General. (2012, 26 de 08 de). Programas de la UE. Obtenido de Proyecto "USo+I: Universidad, Sociedad e Innovación. Mejora de la pertinencia de la educación en las ingenierías de Latinoamérica": http://areadecooperacion.fgua.es/2012/03/ proyecto-alfa-usoi-universidad-sociedad.html.

Vensim www.vensim.com.

Wang, C.-Y., Wu, H.-K., Lee, S. W.-Y., Hwang, F.-K., Chang, H.-Y., Wu, Y.-T., et al. (2014). A review of research on technology-assisted school science laboratories. Educational Technology \& Society, 17(2), 307-320.

Open Access This chapter is licensed under the terms of the Creative Commons Attribution 4.0 International License (http://creativecommons.org/licenses/by/4.0/), which permits use, sharing, adaptation, distribution and reproduction in any medium or format, as long as you give appropriate credit to the original author(s) and the source, provide a link to the Creative Commons license and indicate if changes were made.

The images or other third party material in this chapter are included in the chapter's Creative Commons license, unless indicated otherwise in a credit line to the material. If material is not included in the chapter's Creative Commons license and your intended use is not permitted by statutory regulation or exceeds the permitted use, you will need to obtain permission directly from the copyright holder.

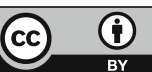

